\title{
openheart Effect of procedural refinement of transfemoral transcatheter aortic valve implantation on outcomes and costs: a single-centre retrospective study
}

\author{
Sivasankar Sangaraju, ${ }^{1}$ Ian Cox, ${ }^{1}$ Malcolm Dalrymple-Hay, ${ }^{1}$ Clinton Lloyd, \\ Venkatesan Suresh, ${ }^{1}$ Tania Riches, ${ }^{1}$ Samantha Melhuish, ${ }^{1}$ Sanjay Asopa, ${ }^{1}$ \\ Samantha Newcombe, ${ }^{1}$ Cornelia Deutsch, ${ }^{2}$ Peter Bramlage (1) ${ }^{2}$
}

To cite: Sangaraju S, Cox I, Dalrymple-Hay M, et al. Effect of procedural refinement of transfemoral transcatheter aortic valve implantation on outcomes and costs: a singlecentre retrospective study. Open Heart 2019;6:e001064. doi:10.1136/ openhrt-2019-001064

Received 4 April 2019 Revised 16 July 2019 Accepted 12 September 2019

Check for updates

(c) Author(s) (or their employer(s)) 2019. Re-use permitted under CC BY-NC. No commercial re-use. See rights and permissions. Published by BMJ.

${ }^{1}$ Cardiology, University Hospitals Plymouth NHS, Plymouth, Devon, UK

${ }^{2}$ Institute for Pharmacology and Preventive Medicine, Cloppenburg, Germany

Correspondence to Prof. Dr. Peter Bramlage, Institute for Pharmacology and Preventive Medicine, Cloppenburg 49661, Germany; peter.bramlage@ippmed.de

\section{ABSTRACT}

Objectives To determine the effect of introducing several procedural refinements of transfemoral transcatheter aortic valve implantation (TAVI) on clinical outcomes and costs.

Design Retrospective analysis comparing two consecutive 1-year periods, before and after the introduction of procedural refinements.

Setting Tertiary hospital aortic valve programme. Participants Consecutive patients undergoing transfemoral TAVI treated between April 2014 and August 2015 using the initial setup ( $n=70$; control group) or between September 2015 and August 2016 after the introduction of procedural refinements $(n=89)$. Interventions Introduction of conscious sedation, percutaneous access and closure, omission of transoesophageal echocardiography during the procedure, and an early discharge procedure.

Outcome measures Procedural characteristics, complications and outcomes; length of stay in intensive care unit (ICU) and hospital; hospital-related direct costs associated with TAVI.

Results There were no statistically significant differences in the incidence of complications or mortality between the two groups. The mean length of stay in the ICU was significantly shorter in the procedural-refinement group compared with the control group (5.1 vs 57.2 hours, $p<0.001$ ), as was the mean length of hospital stay (4.7 vs 6.6 days, $p<0.001)$. The total cost per TAVI procedure was significantly lower, by $£ 3580$, in the procedural-refinement group $(p<0.001)$. This was largely driven by lower ICU costs.

Conclusions Among patients undergoing transfemoral TAVI, procedural refinement facilitated a shorter stay in ICU and earlier discharge from hospital and was cost saving compared with the previous setup.

\section{INTRODUCTION}

Over the last decade, transcatheter aortic valve implantation (TAVI) has emerged as an effective alternative for patients who are poor candidates for surgery. ${ }^{1-5}$ TAVI has become the treatment of choice for symptomatic

\section{Key questions}

What is already known about this subject?

- Transcatheter aortic valve implantation (TAVI) has emerged as an effective alternative for patients who are poor candidates for surgery. While developments continue to be made to improve the devices and techniques used for TAVI, there is less solid data on the effects of non-device related procedural refinement on the outcomes and costs of TAVI.

What does this study add?

- This study adds an evaluation of clinical outcomes and costs of transfemoral TAVI performed before and after the introduction of procedural refinements. The main refinements that were introduced included switching from general anaesthesia to conscious sedation, using percutaneous access/closure in preference to surgical cut-down and omitting periprocedural transoesophageal echocardiography. This introduction of procedural refinements facilitated a shorter stay in ICU, early discharge from hospital and resulted in lower costs.

How might this impact on clinical practice?

- This study provides evidence about the impact of procedural refinements to TAVI on clinical outcomes and costs. These refinements are part of ongoing quality improvement processes and have potential impact on clinical practice.

severe aortic stenosis in patients who are not suitable for surgery, and it is non-inferior to surgical aortic valve replacement in 'highrisk' operable patients. ${ }^{67}$ Furthermore, there is ongoing research into the use of TAVI in intermediate and low risk patients, ${ }^{8-10}$ making TAVI a viable alternative to surgical aortic valve replacement.

While developments continue to be made to improve the devices and techniques used for TAVI, there is less solid data on the effects of non-device related procedural refinement 
on the outcomes and costs of TAVI. First, in the early days of TAVI, general anaesthesia was most commonly used; however, it is also proved to be feasible to perform the procedure using conscious sedation, and this approach has gained favour in some centres. ${ }^{11} 12$ Observational studies suggest that conscious sedation can be used without adversely affecting the overall success or safety of the TAVI procedure ${ }^{13-17}$ and may result in lower costs. ${ }^{18-20}$ Second, percutaneous access and closure has been associated with improvements in patients' comfort and satisfaction as well as in time to haemostasis, but needs to be balanced against periprocedural and anatomic risk factors. ${ }^{21}$ Third, periprocedural transoesophageal echocardiography (TEE) has been extensively used historically, but the focus is shifting from routine use of TEE and general anaesthesia to 'as needed' use. It has been shown that its omission was associated with similar rates of paravalvular leak, similar gradients and velocities across the aortic valve and comparable 30-day outcomes but with a reduced procedure length and length of stay. ${ }^{22} 23$ Finally, postprocedural length of stay has been shown to be a major determinant of patient outcomes and quality of life after surgical and interventional procedures. It is associated with reduced hospital-borne complications, accelerated patient recovery and mobilisation, and lower costs. $^{24-27}$

In summary, TAVI proved to be feasible using conscious sedation without adversely affecting success and safety. Percutaneous access and closure has been associated with advantages for patients comfort as well as in time to haemostasis. Omission of routine use of TEE was associated with similar outcomes. It was for these reasons that we introduced a number of changes to our TAVI procedure in September 2015 in an attempt to make the TAVI procedure more efficient and cost-effective. Primary aim of this report was to evaluate clinical outcomes and secondary aim to evaluate costs of transfemoral TAVI performed before and after the introduction of these procedural refinements.

\section{METHODS}

At our tertiary hospital, the first TAVI was performed in 2008. We introduced several procedural refinements in September 2015 (table 1), and a retrospective analysis was undertaken to compare outcomes and costs associated with transfemoral TAVI procedures during the 1-year period before and the 1-year period after these changes. For this purpose, all consecutive patients who underwent TAVI with an Edwards SAPIEN XT/SAPIEN 3 in the period from April 2014 to August 2015 (before the change; control group) and from September 2015 to August 2016 (after the change; procedural-refinement group) were included in the analysis. NHS Trust protocols for data collection and sharing were observed. Patients and the public were not involved in the design of the study.

\section{Cost data}

Financial data included hospital-related direct costs associated with TAVI, comprising costs of the implantation (procedural costs). These included costs for echocardiography, prosthesis, devices and all costs as part of the implantation procedure. All other costs (ie, pacemaker implantation) were combined as non-procedural costs. Further cost data of interest were analysed (ie, costs in connection with stay on intensive care unit (ICU) or hospital ward, costs for drugs). Costs are reported in UK pounds $(£)$ and were obtained from the department of Finance at University Hospitals Plymouth NHS Trust.

Costs were further categorised into fixed, semi-fixed and variable costs based on acute health clinical costing standards ${ }^{28}$ provided by Healthcare Financial Management Association in the UK (www.hfma.org.uk). Fixed costs are not affected by in-year changes in activity such as rent and rates. Semi-fixed costs are fixed for a given level of activity, but change in steps when activity levels exceed or fall below these given levels; nursing costs are an example. Variable costs are costs that vary with changes in activity, for example, devices (valve, closure device, etc).

Table 1 Catheterisation laboratory layout and hospital stay for TAVI

\begin{tabular}{lll}
\hline & Control group (initial setup) & Procedural-refinement group \\
\hline Anaesthesia & General anaesthesia & Conscious sedation \\
Valve implanted & SAPIEN XT and S3 & SAPIEN 3 \\
\hline Femoral access and closure & Surgical cut-down & $\begin{array}{l}\text { Predominantly percutaneous access and closure using } \\
\text { ProGlide }\end{array}$ \\
\hline Periprocedural echocardiography & $\begin{array}{l}\text { TEE and radiological guidance to facilitate precise valve } \\
\text { positioning }\end{array}$ & Radiologically guided valve positioning; post TAVI TTE \\
\hline Scrub nurse support & $\begin{array}{l}\text { 1 catheter laboratory staff nurse +1 cardiothoracic staff } \\
\text { nurse }\end{array}$ & 1 catheter laboratory staff nurse \\
\hline Postprocedure care & Level 3 care on ICU & Mostly cardiology ward/CCU \\
\hline Length of hospital stay & Minimum 72 hours & 24-72 hours \\
\hline
\end{tabular}

CCU, coronary care unit; ICU, intensive care unit; TAVI, transcatheter aortic valve implantation; TEE, transoesophageal echocardiogram; TTE, transthoracic echocardiography. 


\section{Statistics}

Primary outcomes of interest were procedure-related complications (myocardial infarction, stroke, tamponade, pacemaker (PM) implatation, etc) and death. Secondary outcome parameters were procedural costs and length of stay on ICU as well as in hospital stay.

Data were analysed descriptively; continuous variables were expressed as the mean $\pm \mathrm{SD}$ and categorical variables as number and percentage of the group. The non-parametric Mann-Whitney U test was used for testing statistical significance. A $p$ value of $<0.05$ indicated statistical significance.

\section{RESULTS}

TAVI was performed in 70 patients during the control (pre-change) period and in 89 patients after the introduction of procedural refinements. All patients had aortic stenosis except two who had aortic regurgitation; valve disease was degenerative in all patients except three who had received a previous bio-prosthesis. Patient characteristics are summarised in table 2 . The mean age of patients was $82.4 \pm 7.5$ years in the control group and $80.9 \pm 8.3$ years in the procedural-refinement group. The proportion of women was slightly higher in the control group compared with the procedural-refinement group (48.6\% vs $36.0 \%)$, as was the proportion of smokers $(60.0 \%$ vs $49.4 \%$ ) and patients who had a previous balloon aortic valvuloplasty (28.6\% vs $16.9 \%$ ); however, none of these differences were statistically significant. There were no significant differences in baseline ECG or echocardiographic characteristics between the groups (table 2).

\section{Clinical outcomes}

Procedural characteristics, complications and outcomes are summarised in table 3. Femoral access and closure was generally achieved percutaneously in patients in the

\begin{tabular}{|c|c|c|c|c|}
\hline & $\begin{array}{l}\text { Total } \\
\text { Mean } \pm \text { SD or } n(\%) \\
(n=159)\end{array}$ & $\begin{array}{l}\text { Control group } \\
\text { Mean } \pm \text { SD or } n(\%) \\
(n=70)\end{array}$ & $\begin{array}{l}\text { Procedural-refinement } \\
\text { group } \\
\text { Mean } \pm \text { SD or } n(\%)(n=89)\end{array}$ & $P$ value \\
\hline Age (years) & $81.5 \pm 8.0$ & $82.4 \pm 7.5$ & $80.9 \pm 8.3$ & 0.380 \\
\hline Female gender & $66(41.5)$ & $34(48.6)$ & $32(36.0)$ & 0.109 \\
\hline Smoker former or current & $86(54.1)$ & $42(60.0)$ & $44(49.4)$ & 0.185 \\
\hline Aortic valve pathology & & & & 0.583 \\
\hline Degenerative & $156(98.1)$ & $68(97.1)$ & $88(98.9)$ & \\
\hline Previous bioprosthesis & $3(1.9)$ & $2(2.9)$ & $1(1.1)$ & \\
\hline \multicolumn{5}{|l|}{ Comorbidities/history } \\
\hline COPD & $23(14.5)$ & $9(12.9)$ & $14(15.7)$ & 0.609 \\
\hline Previous stroke & $10(6.3)$ & $4(5.7)$ & $6(6.7)$ & 1.000 \\
\hline Previous myocardial infarction & $36(22.6)$ & $17(24.3)$ & $19(21.3)$ & 0.660 \\
\hline Previous PCl & $23(14.5)$ & $8(11.4)$ & $15(16.9)$ & 0.334 \\
\hline Previous BAV & $35(22.0)$ & $20(28.6)$ & $15(16.9)$ & 0.077 \\
\hline Previous CABG & $37(23.3)$ & $16(22.9)$ & $21(23.6)$ & 0.913 \\
\hline Logistic Euro Score (\%) & $13.1 \pm 9.9$ & $14.4 \pm 11.2$ & $11.8 \pm 8.4$ & 0.217 \\
\hline \multicolumn{5}{|l|}{ ECG and echocardiography } \\
\hline Rhythm & & & & 0.278 \\
\hline Sinus rhythm & $107(67.3)$ & $45(64.3)$ & $62(69.7)$ & \\
\hline Atrial fibrillation & $38(23.9)$ & $16(22.9)$ & $22(24.7)$ & \\
\hline Paced & $14(8.8)$ & $9(12.9)$ & $5(5.6)$ & \\
\hline LVEF & & & & 0.755 \\
\hline$<30 \%$ & $13(8.2)$ & $5(7.1)$ & $8(9.0)$ & \\
\hline $30 \%-49 \%$ & $28(17.6)$ & $11(15.7)$ & $17(19.1)$ & \\
\hline$>49 \%$ & $118(74.2)$ & $54(77.1)$ & $64(71.9)$ & \\
\hline Pulmonary hypertension & $19(11.9)$ & $10(14.3)$ & $9(10.1)$ & 0.421 \\
\hline Mitral regurgitation & & & & 0.612 \\
\hline None or mild & $143(89.9)$ & $62(88.6)$ & $81(91.0)$ & \\
\hline Moderate to severe & $16(10.1)$ & $8(11.4)$ & $8(9.0)$ & \\
\hline
\end{tabular}

BAV, balloon aortic valvuloplasty; CABG, coronary artery bypass graft; COPD, chronic obstructive pulmonary disease; LVEF, left ventricular ejection fraction; $\mathrm{PCl}$, percutaneous coronary intervention. 
Table 3 Procedural characteristics, complications and outcomes

\begin{tabular}{|c|c|c|c|}
\hline $\begin{array}{l}\text { Procedural } \\
\text { characteristics }\end{array}$ & $\begin{array}{l}\text { Control } \\
\text { group } \\
n(\%)(n=70)\end{array}$ & $\begin{array}{l}\text { Procedural- } \\
\text { refinement } \\
\text { group } n(\%) \\
(n=89)\end{array}$ & $P$ value \\
\hline Femoral approach & & & $<0.001$ \\
\hline Surgical & $68(97.1)$ & $0(0)$ & \\
\hline Percutaneous & $2(2.9)$ & $89(100)$ & \\
\hline Femoral closure & & & $<0.001$ \\
\hline Surgical & 68 (97.1) & $3(3.4)$ & \\
\hline Device & $2(2.9)$ & $86(96.6)$ & \\
\hline Valve type & & & $<0.001$ \\
\hline Sapien XT & 37 (52.9) & $1(1.1)$ & \\
\hline Sapien 3 & $33(47.1)$ & $88(98.9)$ & \\
\hline \multicolumn{4}{|l|}{$\begin{array}{l}\text { Complications and } \\
\text { outcomes }\end{array}$} \\
\hline $\begin{array}{l}\text { Myocardial Infarction } \\
\text { (STEMI) }\end{array}$ & $0^{*}(0)$ & $0(0)$ & n.a. \\
\hline Stroke & $2^{\star}(2.9)$ & $0(0)$ & 0.189 \\
\hline Tamponade & $1^{*}(1.4)$ & $3(3.4)$ & 0.632 \\
\hline $\begin{array}{l}\text { Pacemaker implantation } \\
\text { post-TAVI }\end{array}$ & $1^{*}(1.4)$ & $7(7.9)$ & 0.139 \\
\hline $\begin{array}{l}\text { Major access site } \\
\text { vascular complication }\end{array}$ & $2(2.9)$ & $4(4.5)$ & 0.695 \\
\hline $\begin{array}{l}\text { Conversion to open } \\
\text { surgery }\end{array}$ & $1(1.4)$ & $1(1.1)$ & 1.000 \\
\hline $\begin{array}{l}\text { Post-TAVI aortic } \\
\text { regurgitation }\end{array}$ & & & 0.189 \\
\hline None/mild & $67^{\star}(97.1)$ & 89 (100) & \\
\hline Moderate/severe & $2^{*}(2.9)$ & $0(0)$ & \\
\hline Death within 30 days & $2(2.9)$ & $0(0)$ & 0.192 \\
\hline Death within 1 year & $9(12.9)$ & $7(7.9)$ & 0.299 \\
\hline
\end{tabular}

${ }^{*} \mathrm{n}=1$ missing $(\mathrm{n}=69)$.

n.a., not applicable; STEMI, ST-elevation myocardial infarction;

TAVI, transcatheter aortic valve implantation.

procedural-refinement group, whereas surgical cut-down was usually performed in the control group. Approximately half of the patients in the control group received a SAPIEN 3 valve and half received a SAPIEN XT valve. In the procedural-refinement group all except one patient received a SAPIEN 3 valve.

There were no statistically significant differences in the incidence of complications during the hospitalisation time directly after TAVI between the two groups (including major access site vascular complications, conversion to open surgery, myocardial infarction, tamponade, stroke and post-TAVI aortic regurgitation; table 3), although there was a non-significant trend towards a higher pacemaker implant rate in the procedural-refinement group compared with the control group ( $7.9 \%$ vs $1.4 \%, \mathrm{p}=0.139)$. The rate of all-cause mortality
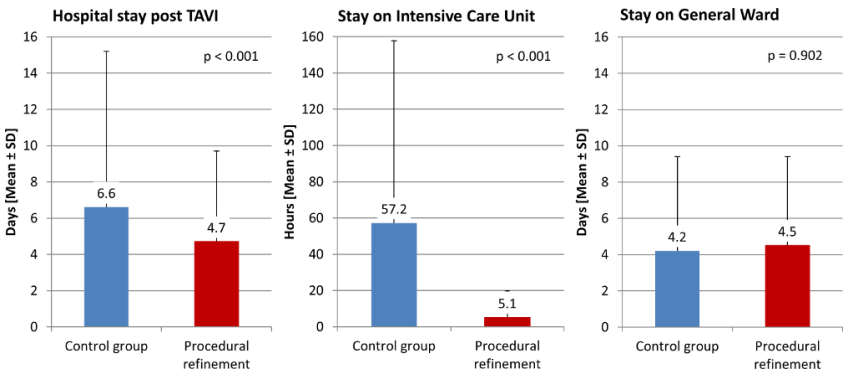

Figure 1 Length of stay in hospital and in the intensive care unit. TAVI, transcatheter aortic valve implantation.

at 1 year was $12.9 \%$ in the control group and $7.9 \%$ in the procedural-refinement group $(\mathrm{p}=0.299)$.

Figure 1 summarises the length of stay in hospital and in the ICU after TAVI. The mean time spent in the ICU after TAVI was significantly shorter in the procedural-refinement group compared with the control group, as was the mean length of stay in hospital. The stay on general ward did not differ significantly between groups.

\section{Costs}

Figure 2 summarises the per-TAVI costs associated with the different pathways. The total cost per TAVI procedure was significantly lower, by $£ 3580$, in the procedural-refinement group compared with the control group (table 4). The procedural cost directly associated to the implantation were significantly higher in the procedural-refinement group compared with the control group (by £2090); however, ICU costs were significantly lower (by £1638), as were drug costs (by £213). Hospital ward costs were also lower in the procedural-refinement group (by £261), but the difference was not statistically significant. These findings are reflected again in the procedural

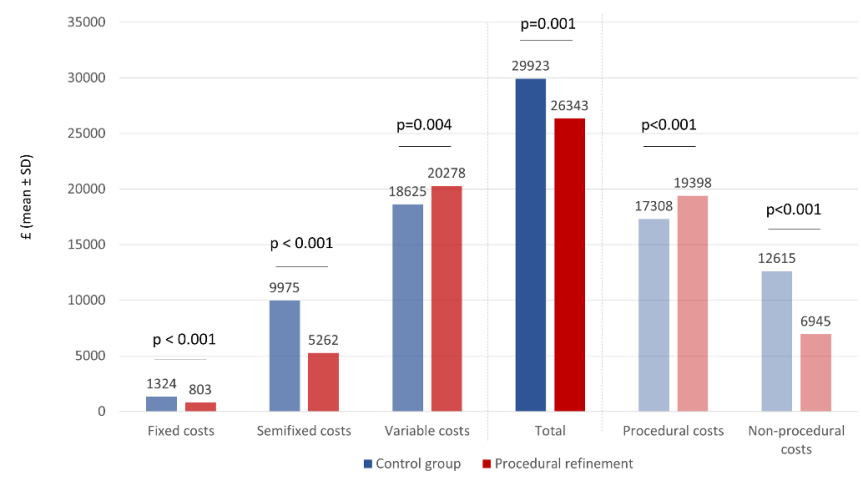

Figure 2 Cost comparison before and after the introduction of procedural refinements. Costs were categorised into fixed, semi-fixed and variable costs based on acute health clinical costing standards ${ }^{28}$ provided by Healthcare Financial Management Association in the UK (www.hfma.org.uk). Fixed costs are not affected by in-year changes in activity such as rent and rates. Semi-fixed costs are fixed for a given level of activity but change in steps when activity levels exceed or fall below these given levels; nursing costs are an example. Variable costs are costs that vary with changes in activity, for example, devices (valve, closure device, etc). non-parametric test used (Mann-Whitney U test). 
Table 4 Cost comparison

\begin{tabular}{|c|c|c|c|c|}
\hline & $\begin{array}{l}\text { Control group } \\
\text { Mean } \pm S D \text { in } £ \\
(n=70)\end{array}$ & $\begin{array}{l}\text { Procedural-refinement group } \\
\text { Mean } \pm \text { SD in } £ \\
(n=89)\end{array}$ & $\begin{array}{l}\text { Mean } \\
\text { difference in } £\end{array}$ & P value \\
\hline Total & $29923 \pm 12168$ & $26343 \pm 6399$ & -3580 & 0.001 \\
\hline Fixed costs & $1324 \pm 1070$ & $803 \pm 454$ & -521 & $<0.001$ \\
\hline Semifixed & $9975 \pm 8132$ & $5262 \pm 2971$ & -4713 & $<0.001$ \\
\hline Variable & $18625 \pm 6250$ & $20278 \pm 4431$ & +1653 & 0.004 \\
\hline \multicolumn{5}{|l|}{ Costs of special interest } \\
\hline Procedural costs (implantation) & $17308 \pm 6023$ & $19398 \pm 4291$ & +2090 & $<0.001$ \\
\hline Intensive care unit & $1838 \pm 3001$ & $200 \pm 574$ & -1638 & $<0.001$ \\
\hline Ward & $1603 \pm 2083$ & $1342 \pm 1267$ & -261 & 0.519 \\
\hline Drugs & $445 \pm 313$ & $232 \pm 144$ & -213 & $<0.001$ \\
\hline
\end{tabular}

Costs were categorised into fixed, semi-fixed and variable costs based on acute health clinical costing standards ${ }^{28}$ provided by Healthcare Financial Management Association in the UK (www.hfma.org.uk). Fixed costs are not affected by in-year changes in activity such as rent and rates. Semi-fixed costs are fixed for a given level of activity but change in steps when activity levels exceed or fall below these given levels; nursing costs are an example. Variable costs are costs that vary with changes in activity,for example, devices (valve, closure device etc.). Non-parametric test used (Mann-Whitney U test).

and non-procedural costs (figure 2). Procedural costs are significantly higher in the procedural refinement group and non-procedural costs are significantly higher in the control group $(\mathrm{p}<0.001$, respectively).

\section{DISCUSSION}

This analysis of transfemoral TAVI procedures performed at a single institution showed that, compared with a control group treated using the previous setup, the introduction of procedural refinements had no adverse effect on TAVI outcomes, but was associated with a reduction in the length of ICU and hospital stay and was cost saving. The main refinements that were introduced included switching from general anaesthesia to conscious sedation, using percutaneous access/closure in preference to surgical cut-down and omitting periprocedural TEE. With adequate proctor guidance, TAVI procedure using conscious sedation and 'refinement' is suited to be adopted by new centres starting TAVI procedures.

In the past, TAVI was usually performed under general anaesthesia and involved periprocedural TEE. However, as experience with TAVI has increased, some centres have moved towards a minimalist approach, whereby the procedure is performed in a catheterisation laboratory using local anaesthesia with or without conscious sedation and without periprocedural TEE. Meta-analyses of observational studies support the use of local anaesthesia/conscious sedation as an alternative to general anaesthesia in appropriate patients undergoing TAVI. ${ }^{16-31}$ This approach reduces the invasive nature of the procedure, as well as potentially reducing the resources required and the costs. ${ }^{18-20}$ It has also been shown that periprocedural TEE can be omitted without compromising outcomes after TAVI, and that this is associated with a reduced procedural time and shorter length of stay in hospital. ${ }^{22}{ }^{32}$ Percutaneous access and closure can be used safely in appropriate patients and can facilitate quicker ambulation and improved comfort for patients. ${ }^{21}{ }^{33}$ These procedural refinements were introduced at our centre without any adverse effects on TAVI outcomes, the incidence of complications or mortality.

Complications that can occur after TAVI include paravalvular leakage/aortic regurgitation, permanent pacemaker implantation, stroke and access-site vascular complications. ${ }^{34} 35$ The incidence of adverse events in the current study are consistent with rates reported previously. ${ }^{34}$ A trend towards a higher rate of post-TAVI pacemaker implantation was noted in the procedural-refinement group compared with the control group, although the difference did not achieve statistical significance. It is possible that this difference could relate to the valves used. At our hospital, the SAPIEN XT valve has been supplanted by the new-generation SAPIEN 3 valve over time. During the control period, patients received either a SAPIEN XT or a SAPIEN 3 valve, whereas during the procedural-refinement period all but one patient received a SAPIEN 3 valve. It was anticipated that this new-generation valve would facilitate the introduction of the procedural refinements such as the use of a conscious sedation pathway, because it uses a smaller diameter $(14 \mathrm{~F} / 16 \mathrm{~F})$ femoral sheath, allows for percutaneous femoral closure and has an improved delivery system to facilitate precise positioning of the valve based on radiological guidance, as well as a new external skirt designed to minimise the risk of significant aortic regurgitation. ${ }^{36}$ An increased rate of pacemaker implantation has been reported with the SAPIEN 3 valve compared with the SAPIEN XT in some (but not all) studies; the risk appears to be declining as experience with the valve increases. ${ }^{37-40}$ There is some evidence the risk may be affected by implantation depth, oversizing and pre-existing right bundle branch block. ${ }^{41}{ }^{42}$ Nonetheless, a 
meta-analysis of studies comparing the SAPIEN 3 and SAPIEN XT valves found that the SAPIEN 3 was associated with a higher rate of successful implantation, fewer perioperative complications and similar rates of permanent pacemaker implantation, cerebrovascular events and early all-cause mortality. ${ }^{43}$

Pressure on healthcare resources means that in addition to optimising outcomes it is important to develop treatment strategies that are cost-effective. Most of the costs associated with the index episode of care for TAVI relate to procedural/hospital-related factors. ${ }^{44}$ In particular, a prolonged stay in the ICU is associated with increased costs, ${ }^{44}$ and periprocedural complications can prolong length of stay and increase costs. ${ }^{45}$ The procedural changes we introduced led to a reduced need for ICU care after the procedure and a shorter overall length of stay in hospital. The mean ICU stay decreased by 52.1 hours and the mean hospital length of stay by 1.9 days in the procedural-refinement group compared with the control group. This is consistent with studies that have found that use of a local anaesthesia/conscious sedation pathway was associated with shorter procedure time and ICU and hospital stays compared with a general anaesthesia pathway, ${ }^{1629-31}$ with a meta-analysis reporting mean differences of -0.18 days for ICU length of stay and -2.09 days for hospital length of stay. ${ }^{16}$ The analysis of costs in the current study showed that the procedural-refinement pathway was cost saving compared with the previous pathway. Although implantation costs were higher for patients in the procedural-refinement group, an overall reduction in costs was seen compared with the previous pathway, predominantly because of a shorter ICU stay. A mean cost saving of $£ 3580$ per TAVI procedure was achieved.

Most studies evaluating the effect of TAVI procedural refinements on costs have focused on the use of conscious sedation versus general anaesthesia pathways. These analyses have found that a local anaesthesia/conscious sedation pathway is cost saving compared with general anaesthesia. ${ }^{14} 1820$ In a study that included a subgroup of patients given SAPIEN XT or SAPIEN 3 valves via the transfemoral route, the total direct cost was approximately $25 \%$ lower in the conscious sedation group compared with general anaesthesia $(\mathrm{p}<0.001)$, with significant reductions seen in each of the individual cost elements considered (anaesthesia, operating-room recovery, ICU, pharmacy and ward). ${ }^{20}$ ICU and hospital lengths of stay were significantly shorter in the conscious sedation group ( 30 vs 61 hours, $\mathrm{p}<0.001$; and 4.9 vs 8.8 days, $\mathrm{p}=0.006$, respectively). ${ }^{20}$ An earlier study, involving transfemoral TAVI with the first-generation SAPIEN valve, also found that a minimalist approach using conscious sedation in a catheterisation laboratory was associated with significantly lower mean hospital costs compared with a standard approach using general anaesthesia in a hybrid operating room (US $\$ 45483$ vs US $\$ 55377, \mathrm{p}<0.001$ ); in this study, hospital costs included the cost of the valve but not physician fees. ${ }^{18}$ Again, a shorter ICU stay (22 vs
28 hours, $\mathrm{p}<0.001$ ) and hospital length of stay ( 4 vs 6 days, $\mathrm{p}=0.01$ ) were seen in the conscious sedation group. ${ }^{18}$

The current study has several limitations. The control group included some patients who received SAPIEN 3 valves as well as patients treated with SAPIEN XT valves; this will have blunted the effect of the higher cost of the SAPIEN 3 valve which would have been more apparent in the procedural-refinement group had there been a strict separation of valve types. However, in a routine clinical practice setting, multiple procedural refinements cannot generally be implemented all at once; there will often be overlap of certain elements over time. This also applies to the type of femoral access/closure used and the use of TEE. This could potentially have affected some outcomes in the study. In addition, the study included a relatively low number of patients. This may have limited the power to detect significant differences; clinically relevant differences may not have translated into statistical significance. Although the number of patients was relatively low, the analysis was based on an unselected consecutive series of patients undergoing transfemoral TAVI at the same centre either before or after the introduction of procedural refinements; data such as this from a realworld setting may be relevant for similar centres that perform TAVI. Finally, procedural refinements such as those described for this study are part of ongoing quality improvement processes which are never completed. As such, the analysis may need to be repeated at other points in the future.

\section{CONCLUSION}

In this study, the overall clinical effectiveness and safety of the procedural refinements for transfemoral TAVI seemed to be equivalent to the former approach, although these findings need to be confirmed in larger studies with longer follow-up time. However, compared with the preceding setup, introducing procedural refinements facilitated a shorter stay in ICU, earlier discharge from hospital and reduced costs.

Contributors SS designed the work, initiated data collection, interpreted the data, revised the manuscript for important intellectual content and released the work for submission. Ian IC, MD-H, CL, VS, TR, SM, SA, SN did the clinical work, were responsible for the data collection, revised the manuscript for important intellectual content and released the work for submission. CD analysed the data, interpreted the data, revised the manuscript for important intellectual content and released the work for submission. PB designed the work, interpreted the data, advised on the statistical analysis, drafted the manuscript and released the work for submission.

Funding Edwards Lifesciences provided funding for the preparation of this manuscript.

Competing interests Peter Bramlage discloses having received research funding from Edwards Lifesciences. Cardiology and Cardiothoracic Departments at University Hospitals Plymouth NHS Trust received an educational grant from Edwards Lifesciences. The other authors have no conflicts of interest to disclose. Patient consent for publication Not required.

Ethics approval Since it was a retrospective study involving anonymised data collection, no ethics committee approval was necessary.

Provenance and peer review Not commissioned; internally peer reviewed. 
Open access This is an open access article distributed in accordance with the Creative Commons Attribution Non Commercial (CC BY-NC 4.0) license, which permits others to distribute, remix, adapt, build upon this work non-commercially, and license their derivative works on different terms, provided the original work is properly cited, appropriate credit is given, any changes made indicated, and the use is non-commercial. See: http://creativecommons.org/licenses/by-nc/4.0/.

ORCID iD

Peter Bramlage http://orcid.org/0000-0003-4970-2110

\section{REFERENCES}

1. Popma JJ, Adams DH, Reardon MJ, et al. Transcatheter aortic valve replacement using a self-expanding bioprosthesis in patients with severe aortic stenosis at extreme risk for surgery. J Am Coll Cardiol 2014;63:1972-81.

2. Mack MJ, Leon MB, Smith CR, et al. 5-Year outcomes of transcatheter aortic valve replacement or surgical aortic valve replacement for high surgical risk patients with aortic stenosis (partner 1): a randomised controlled trial. The Lancet 2015;385:2477-84.

3. Deeb GM, Reardon MJ, Chetcuti S, et al. 3-Year outcomes in highrisk patients who underwent surgical or transcatheter aortic valve replacement. J Am Coll Cardiol 2016;67:2565-74.

4. Kapadia SR, Leon MB, Makkar RR, et al. 5-Year outcomes of transcatheter aortic valve replacement compared with standard treatment for patients with inoperable aortic stenosis (partner 1): a randomised controlled trial. The Lancet 2015;385:2485-91.

5. Young MN, Inglessis I. Transcatheter aortic valve replacement: outcomes, indications, complications, and innovations. Curr Treat Options Cardiovasc Med 2017;19:81.

6. Falk V, Baumgartner H, Bax JJ, et al. 2017 ESC/EACTS guidelines for the management of valvular heart disease. Eur J Cardiothorac Surg 2017;52:616-64

7. Nishimura RA, Otto CM, Bonow RO, et al. 2017 AHA/ACC focused update of the 2014 AHA/ACC guideline for the management of patients with valvular heart disease: a report of the American College of Cardiology/American heart association Task force on clinical practice guidelines. Circulation 2017;135:e1159-95.

8. Leon MB, Smith CR, Mack MJ, et al. Transcatheter or surgical aortic-valve replacement in intermediate-risk patients. N Engl J Med 2016;374:1609-20.

9. Schymik G, Varsami C, Bramlage P, et al. Two-Year Outcomes of Transcatheter Compared With Surgical Aortic Valve Replacement in "Minimal-Risk" Patients Lacking EuroSCORE Co-morbidities (from the TAVIK Registry). Am J Cardiol 2018;122:149-55.

10. Thyregod HGH, Steinbrüchel DA, Ihlemann N, et al. Transcatheter versus surgical aortic valve replacement in patients with severe aortic valve stenosis: 1-year results from the All-Comers notion randomized clinical trial. J Am Coll Cardiol 2015;65:2184-94.

11. Jensen HA, Condado JF, Devireddy C, et al. Minimalist transcatheter aortic valve replacement: the new standard for surgeons and cardiologists using Transfemoral access? J Thorac Cardiovasc Surg 2015;150:833-40

12. Patel PA, Ackermann AM, Augoustides JGT, et al. Anesthetic evolution in transcatheter aortic valve replacement: expert perspectives from high-volume academic centers in Europe and the United States. J Cardiothorac Vasc Anesth 2017;31:777-90.

13. Hyman MC, Vemulapalli S, Szeto WY, et al. Conscious sedation versus general anesthesia for transcatheter aortic valve replacement: insights from the National cardiovascular data registry Society of thoracic Surgeons/American College of cardiology transcatheter valve therapy registry. Circulation 2017;136:2132-40.

14. Attizzani GF, Alkhalil A, Padaliya B, et al. Comparison of outcomes of Transfemoral transcatheter aortic valve implantation using a minimally invasive versus conventional strategy. Am J Cardiol 2015;116:1731-6.

15. Kiramijyan S, Ben-Dor I, Koifman E, et al. Comparison of clinical outcomes with the utilization of monitored anesthesia care vs. general anesthesia in patients undergoing transcatheter aortic valve replacement. Cardiovasc Revasc Med 2016;17:384-90.

16. Villablanca PA, Mohananey D, Nikolic K, et al. Comparison of local versus general anesthesia in patients undergoing transcatheter aortic valve replacement: a meta-analysis. Catheter Cardiovasc Interv 2018;91.

17. Hosoba S, Yamamoto M, Shioda K, et al. Safety and efficacy of minimalist approach in Transfemoral transcatheter aortic valve replacement: insights from the optimized transcatheter vAlvular interventioN-Transcatheter aortic valve implantation (OCEAN-TAVI) registry. Interact Cardiovasc Thorac Surg 2017.
18. Babaliaros V, Devireddy C, Lerakis S, et al. Comparison of Transfemoral transcatheter aortic valve replacement performed in the catheterization laboratory (minimalist approach) versus hybrid operating room (standard approach): outcomes and cost analysis. JACC Cardiovasc Interv 2014;7:898-904.

19. Motloch LJ, Rottlaender D, Reda S, et al. Local versus general anesthesia for Transfemoral aortic valve implantation. Clin Res Cardiol 2012;101:45-53.

20. Toppen W, Johansen D, Sareh S, et al. Improved costs and outcomes with conscious sedation vs general anesthesia in TAVR patients: time to wake up? PLoS One 2017;12:e0173777.

21. Noori VJ, Eldrup-Jørgensen J. A systematic review of vascular closure devices for femoral artery puncture sites. J Vasc Surg 2018:68:887-99.

22. Bhatnagar UB, Gedela M, Sethi P, et al. Outcomes and safety of transcatheter aortic valve implantation with and without routine use of transesophageal echocardiography. Am J Cardiol 2018;122:1210-4.

23. Onishi T, Sengoku K, Ichibori $\mathrm{Y}$, et al. The role of echocardiography in transcatheter aortic valve implantation. Cardiovasc Diagn Ther 2018;8:3-17.

24. Lauck SB, Wood DA, Baumbusch J, et al. Vancouver transcatheter aortic valve replacement clinical pathway: minimalist approach, standardized care, and discharge criteria to reduce length of stay. Circ Cardiovasc Qual Outcomes 2016:9:312-21.

25. Barbanti M, Capranzano P, Ohno Y, et al. Early discharge after Transfemoral transcatheter aortic valve implantation. Heart 2015;101:1485-90.

26. Reynolds MR, Magnuson EA, Wang K, et al. Cost-Effectiveness of transcatheter aortic valve replacement compared with standard care among inoperable patients with severe aortic stenosis: results from the placement of aortic transcatheter valves (partner) trial (cohort B). Circulation 2012;125:1102-9.

27. Reynolds MR, Magnuson EA, Lei Y, et al. Cost-Effectiveness of transcatheter aortic valve replacement compared with surgical aortic valve replacement in high-risk patients with severe aortic stenosis: results of the partner (placement of aortic transcatheter valves) trial (cohort a). J Am Coll Cardiol 2012;60:2683-92.

28. Healthcare Financial Management Association. Acute health clinical costing implementation guide 2014, 2019. Available: https://www. hfma.org.uk/docs/default-source/our-networks/healthcare-costingfor-value-institute/approved-costing-guidance/acute-health-clinicalcosting-implementation-guide-2014-15 [Accessed 31 Jan 2019].

29. Fröhlich GM, Lansky AJ, Webb J, et al. Local versus general anesthesia for transcatheter aortic valve implantation (TAVR)-systematic review and meta-analysis. BMC Med 2014:12:41.

30. O' Sullivan KE, Bracken-Clarke D, Segurado R, et al. Is local anesthesia the optimum strategy in retrograde transcatheter aortic valve implantation? A systematic review and meta-analysis. Thorac Cardiovasc Surg 2014;62:489-97.

31. Maas EHA, Pieters BMA, Van de Velde M, et al. General or local anesthesia for TAVI? A systematic review of the literature and metaanalysis. Curr Pharm Des 2016;22:1868-78.

32. Zaouter C, Smaili S, Leroux L, et al. Transcatheter aortic valve implantation: general anesthesia using transesophageal echocardiography does not decrease the incidence of paravalvular leaks compared to sedation alone. Ann Card Anaesth 2018;21:277-84

33. Kochman J, Kołtowski Łukasz, Huczek Z, et al. Complete percutaneous approach versus surgical access in Transfemoral transcatheter aortic valve implantation: results from a multicentre registry. Kardiol Pol 2018;76:202-8.

34. Durko AP, Osnabrugge RL, Kappetein AP. Long-Term outlook for transcatheter aortic valve replacement. Trends Cardiovasc Med 2018:28:174-183.

35. Terré JA, George I, Smith CR. Pros and cons of transcatheter aortic valve implantation (TAVI). Ann. Cardiothorac. Surg. 2017;6:444-52.

36. Binder RK, Rodes-Cabau J, Wood DA, et al. Transcatheter aortic valve replacement with the SAPIEN 3: a new balloon-expandable transcatheter heart valve. JACC Cardiovasc Interv 2013:6:293-300.

37. Tummala R, Banerjee K, Sankaramangalam K, et al. Clinical and procedural outcomes with the SAPIEN 3 versus the SAPIEN XT prosthetic valves in transcatheter aortic valve replacement: a systematic review and meta-analysis. Cathet. Cardiovasc. Intervent. 2018:92:E149-E158.

38. Binder RK, Stortecky S, Heg D, et al. Procedural results and clinica outcomes of transcatheter aortic valve implantation in Switzerland: an observational cohort study of Sapien 3 versus Sapien XT transcatheter heart valves. Circ Cardiovasc Interv 2015;8.

39. Nijhoff F, Abawi M, Agostoni P, et al. Transcatheter aortic valve implantation with the new balloon-expandable Sapien 3 versus 
Sapien XT valve system: a propensity score-matched single-center comparison. Circ Cardiovasc Interv 2015;8:e002408.

40. Husser O, Kessler T, Burgdorf C, et al. Conduction abnormalities and pacemaker implantations after SAPIEN 3 vs SAPIEN XT prosthesis aortic valve implantation. Revista Española de Cardiología 2016;69:141-8.

41. Rheude T, Blumenstein J, Möllmann $\mathrm{H}$, et al. Spotlight on the SAPIEN 3 transcatheter heart valve. Med Devices 2018;11:353-60.

42. van Rosendael PJ, Delgado V, Bax JJ. Pacemaker implantation rate after transcatheter aortic valve implantation with early and new-generation devices: a systematic review. Eur Heart $J$ 2018;39:2003-13.
43. Ando T, Briasoulis A, Holmes AA, et al. Sapien 3 versus Sapien XT prosthetic valves in transcatheter aortic valve implantation: a metaanalysis. Int J Cardiol 2016;220:472-8.

44. Wijeysundera HC, Li L, Braga V, et al. Drivers of healthcare costs associated with the episode of care for surgical aortic valve replacement versus transcatheter aortic valve implantation. Open Heart 2016;3:e000468.

45. Arnold SV, Lei Y, Reynolds MR, et al. Costs of periprocedural complications in patients treated with transcatheter aortic valve replacement: results from the placement of aortic transcatheter valve trial. Circ Cardiovasc Interv 2014;7:829-36. 